\title{
LIX. Remarks on Mr. Rainey's theory of magnetic reaction
}

\author{
Rev. William Ritchie LL.D. F.R.S.
}

To cite this article: Rev. William Ritchie LL.D. F.R.S. (1836) LIX. Remarks on Mr. Rainey's theory of magnetic reaction, Philosophical Magazine Series 3, 9:54, 287-288, DOI:

10.1080/14786443608648997

To link to this article: http://dx.doi.org/10.1080/14786443608648997

册 Published online: 01 Jun 2009.

Submit your article to this journal $\pi$

Џll Article views: 2

Q View related articles $₫$ 


\section{$\left[\begin{array}{ll}287 & \end{array}\right]$}

LIX. Remarks on Mr. Rainey's Theory of Magnetic Reaction. By the Rev. Wilian Ritchie, LL.D., F.R.S., Professor of Natural Philosophy in the Royal Instilution of Great Britain and in the University of London.

To the Editors of the Philosophical Magazine and Journal.

\section{Gentremen,}

I $\mathrm{F}$ the explanation given by $\mathrm{Mr}$. Rainey, with regard to the 1 reaction of the lifter, (p. 220,) be admitted, it will completely overthrow the Newtouian law of the perfect equality of action and reaction. To save you the trouble of preparing a new cut, I shall use the one employed by Mr Rainey in his last communication. Mr. Rainey takes for granted that a piece of soft iron $B$, placed in the direction of one of the sides of the horseshoe magnet, will have a magnetic power, represented by $b$, induced on its remote extremity, whilst the power of the pole $S$ still retains its inducing power $b$. Now the simplest experiment shows that $\mathrm{S}$ cannot induce a power on a piece of soft iron without having its own power diminished by an equal quantity. If, therefore, $b$ represent the absolute power of

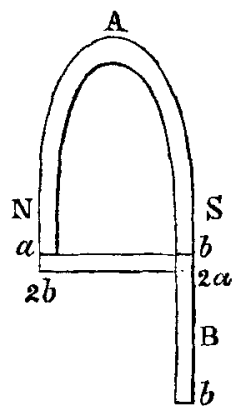
the pole $S$, the magnetism induced at the other extremity of the soft iron must be less than $b$, the diminution depending on the length of $B$. Hence when brought into the position across the poles, the pole $\mathrm{S}$ has not induced the magnetism represented by $a+b$, otherwise its oron magnetism would have been completely destroyed. The sapre remark applies to the pole $\mathrm{N}$. Hence $2 a$ will not represent the magnetism at the pole S, nor $2 b$ that at the pole N. Therefore the contact of the lifter cannot induce the magnetism $a+b$ in the magnet $A$, whatever be its temper or state of magnetism with regard to saturation.

The example which Mr. Rainey gives of increasing the magnetism of a reak magnet, which has been previously magnetized to saturation and has had its magnetism diminished, is one of the most unfortunate examples he could have chosen. I have formerly shown, in the Philosophical Magazine, that if magnetism be induced in one direction and then destroyed, the original magnetic state is easily restored.

The reaction of the soft iron does not therefore create or induce magnetism, it only assists by its reaction in restoring in some measure the weak magnet to its original state: If 
Mr. Rainey can increase the power of a horse-shoe magnet of tempered steel, which has been magnetized in the usual way, to the same strength as the weakened magnet, by means of perfectly soft iron, then it must be admitted that the lifter can by its reaction induce a greater degree of magnetism than the prime motor itself possessed. Till then we must admit the truth of the Newtonian law of action and reaction without exception or reservation.

\section{On the Optical Phanomena of certain Crystals. By H. F. 'TaLBot, Esq., F.R.S.*}

GOME time ago I had the honour to communicate to the Royal Society an account of my invention of the polarizing microscope + . This instrument possesses so great a power of developing the internal structure of transparent bodies, even in their minutest visible particles, that I feel confident the employment of it will lead to many new and interesting resuits. At present I mean to confine myself to the description of a phænomenon which shows strikingly the beantiful order and regularity with which nature disposes the fabric of some of her minutest visible works.

The object I speak of is a kind of minute crystallization which may be obtained in peculiar circumstances, and I doubt not, in many different ways; but the manner in which it has presented itself to my observation is as follows.

A crystal of borax is placed in a drop of phosphoric acid somewhat diluted upon a plate of glass,and then moderately heated until the crystal dissolves in the acid. It is then set aside to crystallize. It is well to prepare a number of these plates at once, varying the relative proportion of the acid and salt, in order that the desired kind of crystallization may be found in one or other of them; for there is a considerable variety in the crystalline forms obtained by this method, some of which indeed are very singular. But when that kind of crystallization takes place which it is more particularly my intention to speak of, the field of view of the microscope is seen covered with minute circular spots, each of which is like a tuft of silk radiating from a centre, and is composed of a close assemblage of delicate acicular crystals forming a star. But besides these, are seen interspersed among them a number of circular transparent bodies, which are evidently modifications of the former,

* Read before the Royal Society May 5th, 1836 : and now communicated by the Author.

+ See Lond. and Edinb. Philosophical Magazine, vol. v. p. 321. 